\section{artelogie}

\section{Artelogie}

Recherche sur les arts, le patrimoine et la littérature de l'Amérique latine

$2 \mid 2012$

Mexique : espace urbain et résistances artistiques et littéraires face à la « ville générique »

\title{
Entrevista a Néstor García Canclini
}

\section{Christine Frérot y Néstor García Canclini}

\section{(2) OpenEdition}

12 Journals

\section{Edición electrónica}

URL: https://journals.openedition.org/artelogie/7558

DOI: $10.4000 /$ artelogie. 7558

ISSN: 2115-6395

\section{Editor}

Association ESCAL

Referencia electrónica

Christine Frérot y Néstor García Canclini, «Entrevista a Néstor García Canclini», Artelogie [En línea], 2 | 2012, Publicado el 21 enero 2012, consultado el 07 enero 2022. URL: http://journals.openedition.org/ artelogie/7558 ; DOI: https://doi.org/10.4000/artelogie.7558

Este documento fue generado automáticamente el 7 enero 2022.

Association ESCAL 


\title{
Entrevista a Néstor García Canclini
}

\author{
Christine Frérot y Néstor García Canclini
}

CHRISTINE FRÉROT - ¿En qué momento de tu reflexión surgió el interés y/o la necesidad de
abordar la cuestión urbana en relación con lo social-cultural como objeto en sí para las
ciencias sociales? ¿Influyó tu experiencia en México durante un periodo en el cuál una de
las ciudades más pobladas del mundo sufrió una transformación drástica?

Néstor García Canclini - Primero, una pequeña aclaración: mi tesis fue efectivamente sobre Merleau-Ponty, pero yo elegí a Merleau porque veía la posibilidad de estudiar en su obra el cruce o las interacciones entre tres corrientes que, en ese momento, eran protagónicas en el movimiento filosófico: la fenomenología, el estructuralismo y el marxismo, que también habían sido parte importante de mi formación en filosofía. De algún modo, aunque era una tesis de filosofía, planteaba la relación de la filosofia con las ciencias sociales y esa era una de las diferencias que yo veía entre Merleau-Ponty, Sartre y otros filósofos de la época. Muy temprano, Merleau puso atención a la relación entre la filosofia empírica y el estudio de la sociedad y de los problemas de comportamiento, de la violencia, de la política, etc...

En cierto modo, ese énfasis en la filosofía se modificó cuando transité mucho más hacia las ciencias sociales y eso ocurrió especialmente a partir de mi llegada a México. Comencé a dar cursos de filosofía y seguí trabajando en teoría social y teoría estética; pero para mí se volvió cada vez más decisivo que el pensamiento filosófico se arraigara en datos empíricos, en el conocimiento de primera mano de procesos sociales y culturales. El descubrimiento de México fue en parte el descubrimiento de las culturas indígenas y de los procesos de mestizaje de América Latina. Por eso, mi primera investigación durante varios años fue sobre las transformaciones de las artesanías y las fiestas tradicionales en contacto con la cultura urbana, los procesos transnacionales, el turismo y otros modos de consumo y de apropiación de las culturas históricas aborígenes.

Ese proceso de apropiación, de conocimiento de las culturas en sus transformaciones contemporáneas, me llevó a tomar conciencia de la importancia de lo urbano y de la escena urbana como el lugar en el que interactúan culturas muy diferentes y donde se hace visible esa interacción. Por eso, después de trabajar en Michoacán siguiendo a 
los artesanos estudié sus itinerarios fuera de los pueblos tradicionales. En mi libro Culturas populares en el capitalismo ${ }^{1}$, documenté la investigación sobre Michoacán y retomé en Culturas híbridas ${ }^{2}$ los problemas de interculturalidad y de hibridación. Pero luego de trabajar entre el año 77 y el 82-83 en Michoacán, comencé a hacer estudios de campo en la frontera norte, especialmente en Tijuana. Me interesaba ver la confrontación entre las culturas de distintas regiones de México que se aglomeraban en la frontera elaborada por migrantes que querían pasar a los Estados Unidos. Muchos no lo lograban e iban formando en la frontera barrios oaxaqueños, zacatecanos, michoacanos, etc.

Era una situación de laboratorio donde se veía con gran dinamismo la capacidad de estas culturas tradicionales para reubicarse y reelaborar su situación de migración. Tanto en los que lograban pasar a San Diego o a Los Ángeles, como los que no pasaban, se producía una interacción muy viva con el inglés y con la cultura estadounidense de California.

CF - ¿Eso generaba un material cultural relevante?

NGC - Hice un primer estudio sobre los efectos que había tenido la instalación del centro cultural más grande que se creó en este periodo, en los años 80 , en la frontera norte, el Centro Cultural de Tijuana, el CECUT. Se construyó un enorme edificio, del tamaño del Museo de Antropologia de México, sin programa cultural. El programa se fue inventando sobre la marcha y la arquitectura se adaptó como pudo a los distintos proyectos que trataban de vincular la cultura mexicana con esa situación de interculturalidad. En una primera etapa, a mediados de los 80 , se intentó hacer programas culturales y artísticos que literalmente afirmaran la cultura y la identidad mexicanas frente a las de los Estados Unidos. Con el tiempo, se vio que esa no era la tarea y los propios habitantes de Tijuana rechazaron ese proyecto concebido en el centro del país. Entonces, lo que se notó con el tiempo fue que había una cultura multiétnica muy compleja en Tijuana y en otras zonas de la frontera, que establecía pactos, conflictos, formas de intercambio muy interesantes con la cultura estadounidense, que también es una cultura multiétnica y compleja.

Esa fue una primera etapa. En 1997 me invitaron a asistir a las experiencias de “inSITE”. En el año 2000, reuní una amplia documentación entrevistando tanto en Tijuana como en San Diego a artistas, receptores y público con una fuerte implicación con las obras. Fue un programa bicultural y binacional de construcción de obras de arte, en muchos casos instalaciones, en otros performances, que los artistas de varios países hacían luego de un periodo de residencia en Tijuana. InSITE tuvo un gran impacto mediático, desde publicaciones hasta programas de radio y una recepción distinta de ambos lados de la frontera.

El programa consistió en invitar a artistas de muchos países a hacer una residencia en Tijuana y producir obras efímeras para luego instalarlas en la frontera. Hubo artistas importantes como Vito Acconci, Helen Escobedo y también otros latinoamericanos, asiáticos y artistas que había en Tijuana que se dieron a conocer a partir de inSITE, como Marcos Ramírez Erre. No era obligatorio que hablaran sobre el tema fronterizo, pero una condición del programa era que antes de concebir sus obras tuvieran la experiencia intercultural de la frontera. Por ejemplo, Ramírez Erre construyó un gran caballo de Troya con dos cabezas y lo instaló en la frontera junto a las casetas de migración. Este caballo tenía una cabeza mirando hacia los EUA y otra hacia México. 
Era transparente, porque Marcos Ramírez decía que "ellos saben todo de nosotros y nosotros todo de ellos". Hizo réplicas de 30 centímetros de ese caballo de madera, que tenía como 15 metros de altura, y las vendía haciendo una parodia de los vendedores de artesanía que se colocan en la frontera.

CF - Finalmente, creo entender que la problemática multicultural de la frontera podría ser más importante que el tema de la ciudad multicultural global. ¿La frontera y las no mans land rebasarían la cuestión de la problemática urbana?

NGC - Sí. Muchos trabajos que se han hecho en los últimos años hablan de un conglomerado urbano binacional, que ven a Tijuana y a San Diego no sólo como dos ciudades, sino como una estructura binacional continua. Hay gente que vive en Tijuana y cruza todos los días para trabajar en San Diego. Cuando hicimos una investigación de antropología visual con Lourdes Grobet ${ }^{3}$, Lourdes fotografió los lugares que los propios habitantes de Tijuana declaraban emblemáticos de la ciudad. Después hicimos grupos focales a los que les mostramos una selección de cincuenta fotos para que eligieran las que a ellos les parecían más representativas y las comentaran, nos dieran un discurso sobre la ciudad de Tijuana, nos contaran relatos y experiencias. Al final, preguntábamos cuáles fotos faltaban. Hubo algunos que nombraban lugares como el Parque Balboa, que está del lado de San Diego, pero para ellos formaba parte del horizonte de Tijuana. Esa experiencia me obligó a preguntarme qué significa la multietnicidad, la recomposición y la reconfiguración de la Ciudad de México, ya que vivo en esa megalópolis.

cF - Cuando llegué a México en 1972 como becada de la UNAM, no había estudios ni carrera de urbanista en la Facultad de Arquitectura. Fue el momento en el cual se hizo patente la necesidad de esta formación y que los estudios empezaron a desarrollarse. Me pareció que se esbozaba entonces la construcción de un "modelo" mexicano de desarrollo urbano diferente al de las grandes urbes latinoamericanas: destruir y conservar, modernizar y patrimonializar, en fin, preservar el patrimonio arquitectónico y al mismo tiempo hacer tabula rasa del pasado.

¿Este "modelo" habrá inspirado a escritores y a artistas durante estos años para formular y reformular el imaginario urbano, creando un fenómeno identitario propio de la ciudad mexicana y sobre todo de la capital? ¿Revelaría una alternancia/oposición de relaciones y choques entre "centro" y "periferia" dentro de la misma urbe?

NGC - Parte de lo que me atrajo de la Ciudad de México fue justamente la coexistencia de ciudades distintas con modelos de desarrollo urbano de varias épocas. Todavía uno puede ver en el Centro Histórico los sitios arqueológicos que atestiguan cómo era Tenochtitlan, ciudad creada hace siete siglos; luego, el trazado del Centro Histórico sigue siendo el de la ciudad colonial, la ciudad diseñada por los españoles con una exuberancia de edificios históricos de los siglos XVII, XVIII y XIX, como no hay en ninguna otra ciudad de América Latina; y luego está la ciudad moderna, posterior a la Independencia y la del siglo XX que coincide con el crecimiento exponencial.

Quizás valga la pena mencionar algunas cifras: en 1940, la Ciudad de México tenía un millón quinientos mil habitantes. En 1950, al final de la primera década de expansión urbana con la migración de otras zonas de la República, llegó a los tres millones. En 1980, no sólo la Ciudad de México, sino toda la zona metropolitana conurbada tenía quince millones de habitantes. Es un crecimiento que no puede compararse al de las ciudades europeas; incluso, en América Latina, la única ciudad que ha crecido tan vertiginosamente fue Sao Paulo. Eso generó una coexistencia en la trama urbana que 
sigue hasta hoy, entre una ciudad precolombina, otra colonial y el desarrollo moderno, expansivo, bastante caótico, en el cual más del cincuenta por ciento de la construcción es autoconstrucción. México es una ciudad que tuvo su primer plan regulador urbano en 1979, cuando ya tenía más de quince millones de habitantes. Esa coexistencia es compleja, pero me parece que ha logrado preservar mucho mejor un patrimonio histórico que en el resto de América Latina. A su vez, se observan otros modelos heterogéneos de modernidad - no hay uno solo -, que tienen que ver, entre otras razones, con la reproducción de modelos de desarrollo urbano estadounidenses en algunas zonas del norte como en Satélite: grandes avenidas, autopistas, una ciudad hecha para el automóvil... La nueva zona de negocios de Santa Fe se inicia en los años 90 cuando el presidente Salinas se propone situar a México como ciudad global y piensa que es dificil rescatar y regenerar una ciudad muy conflictiva y compleja. Prefiere hacer al costado de la ciudad ${ }^{4}$ un emplazamiento muy artificial, en el cual participan grandes despachos arquitectónicos de Nueva York, y crea una ciudad desconectada de la ciudad histórica. La dedica a instalar grandes empresas transnacionales, algunas mexicanas como Televisa y otras europeas $\mathrm{y}$ estadounidenses como Hewlet-Packard, que tienen ahí sus grandes oficinas o sus centros de gestión para toda América latina.

CF - Este tipo de desarrollo de la Ciudad de México, con su historia singular, crea una ciudad de la cual podriamos decir que está en dialéctica urbana y cultural permanente entre lo ultra contemporáneo y lo histórico. ¿Es un modelo original en América Latina?

NGC - Yo no hablaría de un modelo de desarrollo de la Ciudad de México, porque coexisten muchos modelos que se han dado históricamente y hay una superposición de temporalidades. Lo que me parece significativo es cómo la gestión de tantos siglos de desarrollo urbano ha creado una expresividad contradictoria representativa de la manera en la que se han desenvuelto las culturas latinoamericanas. Podríamos comparar esa contradicción latinoamericana con las ciudades europeas y el impacto del postmodernismo en la teorización urbana. Desde los años 70 y 80 , el pensamiento postmoderno tuvo un gran efecto en muchas áreas de la filosofía, del arte, y también en la concepción de lo urbano. En general, se tendió a exaltar el fragmento, la dispersión y descuidar o desvalorizar la idea de la planificación urbana. Se llegó a pensar que no valía la pena planificar las ciudades, sobre todo las megas ciudades y había que aceptar dicha fragmentación. En todo caso, si se quería regenerar el tejido urbano, había que crear focos de gentrificación o de desarrollo popular, sin pretender abarcar la totalidad de la ciudad.

Esa concepción ha sido criticada junto con el pensamiento postmoderno, que tuvo su ciclo hasta finales del siglo XX. Respecto de lo urbano, me parece que tiene el defecto de estar pensada en relación con ciudades que fueron planificadas desde su comienzo y durante su desarrollo histórico. Por ejemplo, las ciudades europeas fueron planificadas desde hace siglos y entraron al siglo XX, al proceso de la modernización y las migraciones, con una estructura muy definida; o el caso de las ciudades modernas estadounidenses, que en su origen también tuvieron planificación y asumieron los nuevos desafíos de las migraciones o de las transformaciones históricas desde estructuras previamente diseñadas.

En América Latina eso no ocurrió. Como decíamos hace un momento, el crecimiento de las ciudades fue muy rápido. En tres o cuatro décadas llegaron millones de migrantes a Lima, Caracas, Sao Paulo, a la Ciudad de México y a muchas otras, y no 
hubo ni tiempo ni capacidad regulatoria para ordenar esa expansión. Entonces son ciudades en las que han tenido que aprender a convivir indisciplinadamente actores muy distintos: actores que estaban acostumbrados a vivir en una ciudad grande con millones de personas y actores que venían del campo o de pueblos pequeños, a veces de culturas muy distintas.

En el caso de México, con sesenta y dos grupos étnicos, la ciudad se convirtió en un resonador de muchas lenguas, de hábitos distintos en la organización del espacio urbano y del espacio doméstico. Se encuentran jardines, usos de la tierra, plantaciones o usos del espacio doméstico muy diferentes. En Nezahualcóyotl, en el norte de la ciudad, hay un tipo de migración campesina del sur del país, (sobre todo de Oaxaca y Chiapas) que se adaptó al estilo de desarrollo industrial. En el sur, la ciudad se ha expandido hacia la carretera a Cuernavaca y hay migración de otro carácter, de clase media y de otras zonas del país.

En realidad somos una ciudad-laboratorio, expresiva de las contradicciones interétnicas y de diferentes etapas históricas del desarrollo de México. Me parece que lo que vuelve muy atractiva a la Ciudad de México es, en parte, esta interculturalidad y transhistoricidad, esta capacidad de hacer convivir muchas etapas del desarrollo histórico.

CF - Si la ciudad es una asociación de imaginarios - artístico, social, etc. - , que se entremezclan creando varias ciudades, una ciudad-museo, ciudad-jardín, ciudad-basura, ciudad-música, ciudad-arte popular, ciudad-arte público, "ciudad perdida"5. ¿Qué suerte de enlaces crean los artistas para aglutinar las diferencias sociales, urbanas y culturales en un espacio público en perpetuo movimiento? ¿Piensas que su intervención, colectiva o individualmente, es indispensable para ayudar a reconstruir una imagen de lo urbano o un imaginario urbano? ¿Será el caso en la historia de la simbologia urbana del Distrito Federal?

NGC - Es una pregunta importante, y a la vez, muy difícil de responder porque cuando uno recorre la historia del arte urbano en México encuentra etapas muy diferentes. Desde luego, podríamos remontarnos al arte urbano precolombino que sigue existiendo y teniendo su papel en la ciudad. Uno va al enorme edificio del Templo Mayor y ve todavía los restos de una ciudad en la que había imágenes e iconografía. Luego, está el arte y la arquitectura coloniales que propusieron una estética de alto valor monumental, muy elocuente, con la concepción de lo urbano que trajeron los españoles y que interactuó con las élites criollas.

En el siglo XX el muralismo ocupó grandes edificios, tanto dentro de ellos como en el exterior. Hay obras de Siqueiros, de Diego Rivera - de Orozco menos -, que contribuyeron a la visualidad urbana. Todo eso quedó en un pasado lejano. Hubo, en parte, por la vocación política de los muralistas y de la gráfica popular, intentos de ocupar el espacio urbano, de decir algo desde el arte en las calles, en las plazas y en las fachadas de los edificios.

En parte es una herencia asumida del papel monumental precolombino y también de la monumentalidad colonial. Había una disputa simbólica por el espacio urbano que tomaron a cargo los muralistas y otros artistas que tenían un mensaje revolucionario que transmitir. Algunos de ellos habían viajado a la Unión Soviética, donde entraron en contacto con el constructivismo y su arte público posterior a la Revolución rusa y trataron de reproducir algunos de esos modelos, pero en clave latinoamericana. Por ejemplo, el mural de Diego Rivera en la escalera principal del Palacio Nacional, muestra tanto obreros rubios - obreros soviéticos - como la complejidad de la 
multiculturalidad mexicana, todo ello incluido en un relato revolucionario que pretende unificar esas distintas corrientes.

La idea de unificación nacional me parece importante en el momento posrevolucionario en el que México se preguntaba cómo ser una nación. Hubo tambíén antropólogos que trabajaron en esta dirección. El libro de Manuel Gamio, Forjando patria, es una especie de manifiesto antropológico acerca de las bases de una nacionalidad que podía ser unificada. Hasta mediados del siglo XX, estos artistas fueron hegemónicos. Los artistas pasaron a tener un papel más discreto, con la aparición del arte geométrico, las vanguardias abstractas, el expresionismo y otras corrientes experimentales que querían prescindir de esa vocación política un poco grandilocuente, donde los artistas se autoadjudicaban un papel histórico central. No han faltado, en las últimas décadas del siglo XX, algunos escultores que han propuesto obras para lugares centrales de la ciudad, por ejemplo la Ciudad Universitaria. Sebastián es el caso más exitoso en vender muchas obras, valioso en un primer momento y luego muy repetitivo. Para mí, el espacio más interesante, que al mismo tiempo es y no es arte urbano, lo constituye el Espacio Escultórico hecho por un colectivo de seis escultores a finales de los años $70^{6}$. Un espacio que está dentro de la Ciudad Universitaria, pero deliberadamente trató de ser más bien un arte de la tierra, un espacio en medio de la vegetación desde donde se puede ver la ciudad, que tiene una cierta autonomía visual y espacial. Me parece una obra magnífica.

CF - El Espacio Escultórico, aparte de su propuesta vinculada a la lava volcánica y a su forma de anfiteatro para presentar conciertos, ¿en qué medida interviene en el surgimiento de un nuevo imaginario urbano?

NGC - No sé si podemos atribuirle un papel importante para el desarrollo del imaginario urbano. Para mí, el arte que más ha contribuido a documentar y a impulsar muchos imaginarios urbanos de la Ciudad de México ha sido la fotografía. México ha tenido extraordinarios fotógrafos, desde Manuel Álvarez Bravo y Héctor García, hasta otros de autoría personal y al mismo tiempo reporteros gráficos, como por ejemplo los hermanos Casasola e incluso fotógrafos contemporáneos que todavía viven y publican sus fotos en los periódicos ${ }^{7}$. Estoy pensando en Marco Antonio Cruz.

Con Alejandro Castellanos y Ana Rosa Mantecón, hice una investigación sobre los imaginarios urbanos en la ciudad, que desembocó en el libro La ciudad de los viajeros ${ }^{8}$. Con Alejandro trabajé los principales archivos fotográficos, como el Archivo General de la Nación, la Fototeca del INAH y varios archivos de artistas individuales como Nacho López. Hicimos una selección de documentación tomando como eje los viajes por la ciudad, partiendo de la idea de que la Ciudad de México es una ciudad donde se dedican muchas horas por día a viajar. Incluso invitamos a un fotógrafo extranjero, Paolo Gasparini, que estuvo nueve meses incorporado a nuestro equipo de investigación y realizó su propia documentación sobre los viajes en la ciudad. Después hicimos grupos focales de gente que viaja intensamente por la ciudad: un grupo de repartidores de alimentos que se desplazaban en camiones todos los días; otro de policías que regulaban el tráfico; uno de madres que llevaban niños a la escuela; otro con estudiantes que vivían lejos de los lugares donde estudiaban. Nos interesaban también otros habitantes de la ciudad en la situación de viajar, su experiencia y el imaginario generado al atravesar zonas de la ciudad que no conocen pero les suscitan percepciones acerca de cómo se vive ahí, cómo viven los otros, los que son distintos. 
A mí me parece que el Espacio Escultórico es una extraordinaria obra arquitectónicoartística. Está emplazada en un lugar de descanso dentro de la ciudad, en medio de la vegetación, donde uno va de visita a tener una experiencia y a veces, sobre todo en otra época-ya no se hace-, a escuchar conciertos. Después de construirla se descubrió que tenía excelente acústica. Se han realizado experiencias de música y danza sobre la lava volcánica que forma el suelo del Espacio Escultórico. En cambio cualquier exposición de fotografía sobre la Ciudad de México nos inserta en el tráfico, en el ruido urbano.

CF - En tu artículo "Villes-spectacles et villes-paranoïaques" 9 hablas de ciudadesespectáculo, de ciudades "sexy", de ciudades-globales... Quisiera saber si México tiende a seguir siendo una "ciudad global" o conserva, en su evolución de "ciudad-espectáculo", un aspecto sui generis. Pienso en la revitalización de barrios del Centro Histórico y en su progresiva apropiación, primero por los artistas y los intelectuales, después por el pueblo citadino en su conjunto.

NGC - En las listas de ciudades globales que se vienen haciendo desde hace unos veinte años, desde el libro fundacional de Saskia Sassen -en el que sólo se ocupaba de Londres, Nueva York y Tokio-, se han ido sumando muchas otras ciudades que tienen esta característica de globalización, en el sentido de ser nodos que atraviesan redes globalizadas de comunicación, que tienen un alto porcentaje de turismo internacional y desarrollan en su interior focos de creatividad, de producción industrial y sobre todo de industrias no contaminantes, digitales y de comunicaciones que tienen una expansión transnacional.

De modo atípico la Ciudad de México está, sin duda alguna, en esta serie. No como una ciudad que se transforma enteramente en ciudad global, sino que tiene enclaves globalizados, algunos evidentes, como lo que mencionábamos de Santa Fe o el Centro Histórico a partir del sismo de 1985 que destruyó gran parte de los edificios. Se tomó conciencia de que había que restaurar los edificios del siglo XVIII y XIX, habilitarlos como lugares para la convivencia pública donde el comercio, el turismo y las habitaciones tuvieran posibilidades de coexistir. Se ha hecho una gran obra en este sentido por parte de los dos últimos gobiernos de la ciudad. Alejandra Moreno Toscano, que es una de las figuras importantes en la investigación urbana sobre el Centro Histórico; está a cargo de estos trabajos.

Algunos grandes empresarios ${ }^{10}$ han invertido comprando edificios o tratando de contribuir a la restauración de espacios públicos. Se han habilitado calles peatonales, se trata de homogeneizar un poco y de restaurar el sentido histórico de los edificios. Existe una legislación rigurosa para preservar la visualidad urbana y sin duda es un lugar muy logrado, reconocido internacionalmente.

CF - La historia de las experiencias colectivas, como fueron en los 90 "La Panaderia", "La Quiñonera", "Temístocles" y hoy "Soma", demuestran, como en Oaxaca en 2006, que los artistas deben actuar colectivamente para que haya una mínima incidencia en la resistencia a lo que el arquitecto holandés Rem Koohlas Ilama "la ciudad genérica". ¿Me podrías hablar de este paso de lo individual a lo colectivo en el espacio público?

NGC - Estas experiencias que mencionas han sido innovadoras. Han construido grupos o públicos en torno a lugares de exhibición, pero principalmente en lugares cerrados. Quizás lo que debe reconocerse en estos ejemplos de los 90, como en algunos que subsisten como Soma y en otros centros culturales que dependen del Estado, -como el Laboratorio de Arte Alameda, el Museo de Arte Carrillo Gil, el Ex 
Teresa Arte Actual, o el Centro Cultural de España-, es que se han convertido en focos de atracción de las nuevas generaciones de artistas y de públicos interesados en el arte de los jóvenes. Siendo lugares interdisciplinarios e intermediales, combinan las artes visuales con la música, eventos, instalaciones digitales. Aunque suceden en el interior de centros culturales cerrados que, en algunos casos, tendían a degradarse, tienen un efecto urbano porque logran reactivar espacios públicos al generar nuevas formas de actividad cultural abierta. En la calle que está entre el Centro Cultural de España y la Catedral, se baila en la calle, se logra ocupar el espacio público con una presencia social significativa.

Creo que sería el efecto urbano más importante de estas experiencias, aunque me parece que en los últimos años no podemos hablar de un arte urbano como el que hubo en otros períodos. Agregaría a los ejemplos que mencionamos del muralismo, otras experiencias más recientes: los grupos de los años 70 y principios de los 80; por ejemplo el Grupo Suma que hizo un arte deliberadamente urbano con placas repetitivas, creando logotipos del empleado público, del trabajador urbano y multiplicándolo en la ciudad. En fin, no hay en el último tiempo muchas experiencias en este sentido. Tiene que ver, me parece, con la aceptación que en las ciudades tan grandes se vuelve medio utópico pretender tener una presencia como arte urbano. Todavía la tienen los músicos, los que hacen grandes conciertos, pero es difícil hacer lo que Mathias Goeritz pretendió con la Ruta de la Amistad en el 68, realizar señalamientos con obras de grandes escultores contemporáneos que en los veinte últimos años han sido tragadas por la construcción de edificios más altos o por la complejidad de las autopistas dentro de la ciudad.

CF - Lo que hoy cuenta para los artistas es crear focos alternativos y de resistencia; focos que oponen una resistencia al mercado, a la generalización homogeneizante del arte globalizado. ¿Cómo interpretarías la proliferación reciente de "guías" y revistas sobre la "nueva Ciudad de México"11 y la reciente expansión de los museos de arte ${ }^{12}$ en la construcción de otro "orden urbano", que coinciden con su apropiación por nuevos consumidores culturales?

NGC - Son varios fenómenos que me parecen interesantes. Uno consiste en la multiplicación de focos de creatividad, de artes visuales, artes intermediales donde hay plástica, video, performance, teatro y que se desarrollan en toda la ciudad, principalmente en algunas zonas del Centro Histórico y de dos áreas muy gentrificadas que son la Colonia Condesa y últimamente la Roma. Es dónde más emergen restaurantes, casas de diseño y también "casas vecinas" - para usar el nombre de uno de estos centros - pensadas para que los artistas se reúnan con escritores, creadores o diseñadores. Esto tiene una efervescencia extraordinaria. De hecho, es lo que estoy estudiando ahora: cómo son las nuevas estrategias creativas de los artistas que no logran llegar a los grandes museos, a quienes a veces ni les interesa exhibir en las galerías comerciales o de proyección internacional y prefieren insertarse en la comunidad, tener una relación viva con procesos sociales contemporáneos.

Esta investigación sobre estrategia creativa de los jóvenes, la estamos haciendo simultáneamente con un grupo de antropólogos de Madrid que estudian lo que ellos llaman "las prácticas emergentes" en la vida urbana de Madrid. Tiene que ver también con los trend-setters jóvenes que toman posición en las nuevas tendencias expresivas. Éstos trabajan en proyectos transitorios de corta duración, consiguen múltiples financiamientos y buscan fondos con el Consejo Nacional para la Cultura y 
las Artes, en Televisa, en Jumex ${ }^{13}$, donde pueden. Juntan pequeños aportes de distintos actores públicos y privados para desarrollar proyectos autónomos e independientes. En este sentido, diría que sí es una cultura de resistencia al mercado, a la hegemonía de los organismos públicos, pero sobre todo es autónoma e intenta desarrollar nuevas vías de expresividad y de comunicación.

Quiero agregar algo sobre las revistas. Existen más de quince revistas: puedes encontrar la mayoría en las librerías de Sanborns. A las que tú citas (Chilango, Frente, Algarabía), yo agregaría Picnic, La Tempestad. Lo que representan estas revistas es, por un lado, la integración interdisciplinaria, es decir a quienes les interesa las artes visuales les interesa también el diseño y las formas de experimentación en los estilos de vida, tanto la salud y la moda como muchas otras zonas de la vida social. A quienes les interesa la moda también les puede interesar las artes visuales, el teatro, el cine, el video. Estas revistas con proyectos distintos tratan de articular lo que en la sociedad se está dando al mismo tiempo. Los estatutos cerrados (artista, músico, diseñador) tienen cada vez menos vigencia. Hay proyectos diferentes, hay revistas más fashion como Celeste, Chilango y hay otras más reflexivas, más críticas, de replanteamiento de la escena cultural como La Tempestad, quizá la más elaborada en este sentido.

CF - Quiero saber si todavía estás de acuerdo con esta cita de Carlos Monsiváis que mencionas en uno de tus libros y que decía que "México es una ciudad postapocalíptica porque lo peor ya ha pasado".

NGC - Es la típica ironía monsivaisiana de jugar con el absurdo. Significa que quienes vivimos en la Ciudad de México hace mucho tiempo que tenemos la experiencia de que el Apocalipsis está a la vuelta de la esquina, que salir a la calle, subirse al transporte público o manejar el propio coche es entrar en lo imprevisible. Uno nunca sabe cuánto tiempo le va a llevar ir de una parte de la ciudad a la otra. En medio del tráfico seguramente se va a encontrar cada día con diez, quince manifestaciones de protesta, o que se cortó la luz y no funcionan los semáforos... En fin, muchas alteraciones del mínimo orden que existe en la ciudad. La experiencia de lo apocalíptico se vuelve habitual y en este sentido Monsiváis dice que vivimos en una ciudad postapocalíptica, porque todos nos acostumbramos a ese desorden. Tiene que ver con la complejidad intercultural, con la protesta ante el malestar constante y no sólo de la ciudad, porque a la Ciudad de México vienen a protestar de todo el país. En el Zócalo, esa magnífica plaza principal vacía donde sólo hay una bandera, uno encuentra que no puede cruzarla porque está llena de tiendas de campaña - ahora mismo está el Sindicato de Luz y Fuerza-manifestaciones de gente de Oaxaca, Zacatecas, Morelos, etc., que vienen a protestar porque en la Ciudad de México está el gobierno nacional.

Eso también puede verse en otras ciudades del mundo: el uso de recursos de las instalaciones, de los performances por parte de movimientos sociales alternativos a los cuales se asocian, a veces, los artistas.

CF - ¿Me podrías hablar un poco sobre lo que estás trabajando ahora?

NGC - Como te dije estamos haciendo una investigación sobre estrategias creativas de los jóvenes y de las nuevas redes culturales. Mucho de lo que sucede no ocurre como fenómeno urbano sino en la red. A veces interactúa con el espacio urbano: se documenta en la red lo que pasa en la ciudad, se comunica la gente a través de redes deslocalizadas Hemos hecho entrevistas y observaciones etnográficas en los múltiples 
lugares donde se juntan los jóvenes: conciertos y redes de comunicación digital de música o en las numerosas editoriales independientes de jóvenes.

El año pasado hubo una Feria del Libro Independiente que se hizo en la principal librería de la ciudad, la del Fondo de Cultura Económica en la Condesa. Le cedieron un gran espacio de la librería para que cincuenta editoriales exhibieran lo que hacen de forma alternativa. Últimamente, estamos incorporando lo que sucede con los festivales de cine independiente. En febrero pasado, hubo tres festivales simultáneos: uno muy grande, llamado Ambulante, que se realizó en más de cien sedes en la Ciudad de México, tanto en cines comerciales como en centros culturales independientes. Y luego, se repitió en todo el país en doce ciudades. Está también en la red, se opera por Facebook, Twitter, hay películas, cortometrajes y documentales que se suben a Youtube.

Se ha establecido una red muy extensa de proyecciones, de públicos y de formación de nuevos públicos que se articulan fuera del sistema comercial controlado por Hollywood. Hay una emergencia fuerte de artistas jóvenes, comunicadores, actores culturales y promotores que están desarrollando un nuevo tipo de configuración que todavía no entendemos bien qué es. Es bastante global. Hay lugares donde ya se han realizado algunos estudios: en Gran Bretaña se les llaman "ciudades creativas" o "economía creativa"; en España, el año pasado se publicaron dos primeros estudios sobre lo que llaman el "emprendizaje cultural", o sea jóvenes emprendedores que se organizan en pequeñas empresas, a veces de corta duración, pero logran impulsar formas nuevas de comunicación cultural, a veces modelos de negocio cultural distintos y formas autogestionadas.

Sigo muy interesado en lo que he publicado en mi último libro ${ }^{14}$ sobre cómo los artistas de distintos países están buscando hacer relatos sobre lo que está sucediendo en sus sociedades o en el extranjero y con los migrantes en el mundo. Ensayan formas nuevas de comunicación como las de León Ferrari, Antoní Muntadas, Carlos Amorales, Gabriel Orozco y Francis Alÿs. Trato de ver qué significa esto para replantear las instituciones y repensar lo que entendemos por patrimonio cultural. También me interesa ver la emergencia de estos nuevos movimientos juveniles que están haciendo explotar las estructuras históricas, rutinarias, demasiado institucionalizadas.

\section{NOTAS}

1. García Canclini, Néstor (1982) Culturas populares en el capitalismo, México: Editorial Nueva Imagen; $6^{a}$ edición ampliada (2002), México: Grijalbo.

2. García Canclini, Néstor (2001) Culturas híbridas. Estrategias para entrar y salir de la modernidad. $1^{\text {a }}$ edición actualizada, Argentina: Editorial Paidós. Traduction anglaise (2001) Hybrid Cultures: Strategies for Entering and Leaving Modernity. Colección: Cultural Studies of the Américas. Estados Unidos: Universidad de Minnesota Press.

3. Fotógrafa mexicana. 
4. Sobre un enorme basurero público.

5. Mexicanismo para indicar los asentamientos irregulares y pobres en zonas periféricas de las ciudades.

6. Helen Escobedo, Manuel Felguérez, Mathias Goeritz, Hersú,a Sebastían y Federico Silva.

7. Como fue el caso de Enrique Metínides.

8. La ciudad de los viajeros. Travesías e imaginarios urbanos: México 1940 - 2000, México: Grijalbo y Universidad Autónoma Metropolitana, 1996, 111 pp. En proceso de reedición en el Fondo de Cultura Económica.

9. Sociologie et sociétés, "Le spectacle des villes/The Spectacle of Cities", sos la direction de Anouk Bélanger et Jean-François Côté, vol. 37, n 1, Les Presses de l'Université de Montreal, 2005, pp. 151-170.

10. Entre los cuáles está Carlos Slim.

11. Citámbulos, A dónde vais Monsivais, Nueva guía del Centro Histórico, Chilango, Frente (gratuita), Algarabía, Picnic, La Tempestad, Celeste.

12. En México D.F., como el MUAC, y generalistas e históricos como el Museo del Estanquillo y el Centro Cultural Estación Indianilla, o el Museo del Objeto.

13. Fundación Jumex. Colección privada de arte contemporáneo, México.

14. La sociedad sin relato, Antropologia y estética de la inminencia, Katz Editores, Buenos Aires, 2010, $264 \mathrm{p}$.

\section{RESÚMENES}

Néstor García Canclini ha llevado a cabo una profunda reflexión sobre la ciudad, echando mano de diferentes disciplinas que van desde la filosofía y la estética hasta la historia, pasando por la sociología y la antropología. Su llegada a México implicó un cambio en su interés original por la filosofía. Al entrar en contacto con la historia de este país y al descubrir sus diversas culturas, Nestor García Canclini se acercó a las ciencias sociales desarrollando el concepto de «culturas híbridas» y confirmando su intéres para los fenómenos culturales y su profundo anclaje social. En esta entrevista con Christine Frérot, el investigador recorre algunas de sus experiencias vividas en las ciudades mexicanas. El caso de Tijuana es ejemplar de la articulación entre la urbe y los procesos culturales. Es ahí que nació la participación de García Canclini en el programa artístico "Insight", en el que la diversidad cultural fronteriza ocupa un lugar central del proceso creativo. Más tarde, la Ciudad de México le proporcionó el material para reflexionar profundamente acerca de la relación entre lo urbano y lo cultural. Comprobó que en la megalópolis mexicana, a pesar del caós, el patrimonio histórico y cultural coexisten al lado de modelos de urbanización, importados principalmente de los Estados Unidos; lejos de frenar la creación, la dinámica generada cataliza nuevas formas y nuevas temáticas de orden cultural y artístico.

Nestor García Canclini a développé une profonde réflexion sur la ville à partir de différentes disciplines qui vont de la philosophie à l'esthétique et à l'histoire, en passant par la sociologie et l'anthropologie. Son arrivée au Mexique va provoquer un changement dans son rapport exclusif à la philosophie. Le contact avec l'histoire de ce pays et la découverte de ses diverses cultures vont amener Nestor García Canclini à se rapprocher des sciences sociales en développant le concept de « cultures hybrides » et à confirmer son intérêt pour les phénomènes culturels et leur ancrage dans le champ social. Dans cette entrevue avec Christine Frérot, le chercheur parcourt 
quelques-unes des diverses expériences auxquelles il a participé dans plusieurs villes mexicaines. Le cas de Tijuana est particulièrement exemplaire de l'articulation entre la ville et les processus culturels. C'est de là qu'est née sa participation au programme artistique «Insight » dans lequel la diversité culturelle de la frontière occupe une place centrale dans le processus créateur. Mexico va lui apporter plus tard le matériel pour réfléchir en profondeur sur la relation entre la dimension urbaine et la production culturelle. En observant la mégalopole mexicaine, García Canclini montre que le patrimoine historique et culturel coexiste, malgré le chaos, aux côtés des modèles d'urbanisation principalement importés des Etats-Unis; loin de mettre un frein à la création, la dynamique générée suscite, au contraire, de nouvelles formes et thématiques d'ordre culturel et artistique.

\section{ÍNDICE}

Palabras claves: Ciudad de México, culturas urbanas, Tijuana, inSITE, Espacio escultórico, nuevas estrategias creativas, revistas culturales

\section{AUTORES}

\section{CHRISTINE FRÉROT}

Tras una tesís en filosofía sobre Merleau-Ponty, has teorizado sobre las culturas híbridas en América Latina. Has dedicado tus últimos años, entre otros temas, a numerosos estudios y análisis sobre las relaciones entre lo social, lo político, lo cultural y el ámbito urbano. - México D.F., mayo 2011

\section{NÉSTOR GARCÍA CANCLINI}

(Argentina, 1939) es Doctor en Filosofía por las universidades de París y de La Plata. Ha sido profesor en las universidades de Austin, Duke, Stanford, Barcelona, Buenos Aires y São Paulo. Recibió la Beca Guggenheim, el Premio Ensayo Casa de las Américas en reconocimiento a Culturas populares en el capitalismo y el Book Award de la Asociación de Estudios Latinoamericanos por el libro "Culturas híbridas. Estrategias para entrar y salir de la modernidad". Otros trabajos destacados son "Consumidores y ciudadanos", "La globalización imaginada" y "Diferentes, desiguales y desconectados: mapas de la interculturalidad". En la actualidad enfoca su investigación en las relaciones entre estética, arte, antropología, estrategias creativas y redes culturales de los jóvenes. 